\title{
Dominant Firms, Imitation, and Incentives to Innovate
}

\author{
Luís Cabral* \\ $N Y U$ and $C E P R$
}

\author{
Ben Polak* \\ Yale University
}

January 2007

\begin{abstract}
We provide a simple framework to analyze the effect of firm dominance on incentives for R\&D. An increase in firm dominance, which we measure by a premium in consumer valuation, increases the dominant firm's incentives and decreases the rival firm's incentives for R\&D. These changes influence the probability of innovation through two effects: changes in total R\&D effort and changes in how this total is distributed between the two firms.

For a given level of total research effort, the shift from the rival firm to the dominant firm is a good thing as it decreases the likelihood of duplicate innovation (we call this the duplication effect). However, the shift in research effort is not one-to-one. The dominant firm's benefit from increased dominance is more inframarginal than marginal when compared to the rival firm's disincentive. As a result, total research effort decreases when firm dominance increases (we call this the total effort effect).

We show the total effort effect dominates the duplication effect when intellectual property protection is weak, and the opposite when property rights are strong. That is, firm dominance is good for innovation when (but only when) property rights are strong. We also examine consumer and social surplus.
\end{abstract}

*lcabral@stern.nyu.edu and benjamin.polak@yale.edu. During AY2006-2007, Cabral is visiting the Department of Economics, Yale University. We thank Pedro Marín, Mike Riordan, and various seminar audiences for useful comments and suggestions. The usual disclaimer applies. 


\section{Introduction}

The economic analysis of innovation incentives has received considerable attention in both theoretical and empirical industrial organization. Some of the main questions that have been addressed include (a) the relation between market structure and innovation incentives, (b) the relation between the private and the social optimum innovation rates, and (c) the importance of innovation spillovers. ${ }^{1}$

The recent evolution of various high-tech industries has brought forth a new set of issues, in particular the positive and normative implications of market dominance in terms of innovation incentives, especially in a context where imitation is relatively easy. For example, much of Microsoft's economic advance has primarily resulted from imitation and gradual innovation, not from drastic innovation: Excel owes much to Lotus 123; Microsoft Word followed the lead of several other popular word processors; Microsoft's Power Point was inspired by programs such as Harvard Graphics or Freelance; and so forth.

In some respects, Microsoft's products have brought about a significant benefit to consumers. If consumers buy them, it is largely because they value them more than competing products. However, one fears that, in the long run, such imitation-and-improvement strategy may decrease the incentives for other firms to innovate:

Today, Microsoft so completely dominates each of these markets that few venture capitalists would even consider funding new programs that would seek to dislodge it. Microsoft is not only successful, it seems unbeatable in the PC applications markets. ${ }^{2}$

Nor is this problem limited to Microsoft:

In some niches of the software business, Google is casting the same sort of shadow over Silicon Valley that Microsoft once did. "You've got people who don't even feel they can launch a product for fear that Google will get in." 3

\footnotetext{
${ }^{1}$ See Reinganum (1989) for a survey of the main theoretical approaches and Cohen and Levin (1989) for a survey of the empirical evidence. Below we provide more detailed references.

2 "What To Do About Microsoft?" by Ralph Nader and James Love, Le Monde Diplomatique, November 1997.

3 "Microsoft And Google Set to Wage Arms Race," by Steve Lohr and Saul Hansell, The New York Times, May 2, 2006.
} 
Our purpose in this paper is to provide a simple framework with which to analyze the impact of firm dominance on incentives for $R \& D$. We consider a model where two firms invest in $R \& D$ with the goal of finding a product of higher quality. Specifically, we consider a two-stage model comprising R\&D competition and then price competition. Our model has three important features. First, we assume that property rights are imperfect, so that a lagging firm can (imperfectly) imitate the leader. Second, firms' R\&D levels are substitutes from a social point of view and strategic substitutes from a firm point of view. Third, we assume that one of the firms is dominant, in the sense that, everything else constant, its product is worth more in the eyes of consumers.

Modeling of a dominant firm is the most distinctive feature of our paper with respect to previous approaches to innovation and product market competition; it thus warrants some additional discussion. We do not assume that the dominant firm is better at performing $R \& D$ or imitating other firms' $R \& D$. Rather, we assume that, for a given set of product quality outcomes resulting form innovation and imitation, one of the firms (the dominant firm) is able to add value to its product in a way that other firms are not. We model this in a reduced form by assuming consumers are willing to pay an extra amount, $b$, for the dominant firm's product (everything else constant).

There may be various underlying sources of the value $b$, the parameter that defines firm dominance. It may be that the dominant firm has a more popular brand or greater reputation for product quality. It may also be the case that the dominant firm possesses complementary products which better interact with its product than with the rivals' products. ${ }^{4}$ Whichever is the case, the important thing is that, everything else constant, consumers are willing to pay more for the dominant firm's product. ${ }^{5}$

While we are ultimately interested in the welfare effects of firm dominance, we start by looking at the effects of firm dominance on the probability of innovation (Section 3). An increase in firm dominance, which we measure by a premium in consumer valuation, increases the dominant firm's incentives and decreases the rival firm's incentives for R\&D. These changes influence the

\footnotetext{
${ }^{4}$ For example, by controlling the operating system and other applications, Microsoft is better able to integrate each piece in the whole PC/Windows platform in a way that adds value to its applications. In the words of Jim Allchin, Senior Microsoft Vice President, "innovation through integration is the engine that drives the computer industry, bringing the benefits of computing to hundreds of millions of people." See http://www.actonline.org/pubs /hostage/hostage101.asp January 27, 1999.

${ }^{5}$ In Section 6 we contrast the case when consumers pay a premium $b$ for the dominant firm's product to the case when they place a value discount $d$ on the rival firm's product. Some of our result remain valid, some do not.
} 
probability of innovation through two effects: changes in total $R \& D$ effort by the two firms and changes in how this total is distributed between the two firms.

For a given total level of research effort, the shift in research effort from the rival firm to the dominant firm is a good thing as it decreases the likelihood of duplicate innovation: in the limit, it is better to have one firm innovating with probability $r$ than two firms innovating with probability $r / 2$ each. However, the shift in research effort is not one-to-one. The dominant firm's benefit from increased dominance is more inframarginal than marginal when compared to the rival firm's disincentive. As a result, total research effort decreases when firm dominance increases.

Which of the two effects dominates depends on the degree of property rights, which we model by an imitation lag. When the imitation lag is high (strong property rights), the equilibrium levels of research are high. We show this implies that the total effort effect is low, whereas the duplication effect is high. As a result, the probability of innovation increases with firm dominance. When imitation lags are low (weak property rights), the equilibrium levels of research are low. This implies that the duplication effect is negligible, whereas the total effort effect is high. As a result, the probability of innovation decreases with firm dominance.

These effects on the probability of innovation carry over to consumer and social surplus (Sections 4 and 5). In fact, if the gains from innovation are sufficiently high, then consumer and social surplus increase if and only if the probability of innovation increases. However, there are cases when the probability of innovation increases but consumer surplus does not. The reason is that firm dominance implies a lower probability of duplication. Reducing duplication is good in terms of probability of innovation but bad from the consumers' point of view (a second innovator increases consumer surplus through price competition). There are also cases when the probability of innovation does not increase but social surplus does. The reason is that firm dominance has a positive direct effect on social value, in addition to the indirect effect through changes in the probability of innovation.

Related literature. As mentioned earlier, there is an extensive theoretical literature that examines the relation between market structure and innovation incentives. Most authors consider a winner-take-all model. ${ }^{6}$ Others

\footnotetext{
${ }^{6}$ In some cases, the winner is the firm that pays the most (e.g., Gilbert and Newbery, 1982); in other cases, the probability of winning is smoothly increasing in investment, either
} 
consider two-stage models, with independent R\&D investments in the first period and product market competition in the second period. ${ }^{7}$ We follow the latter tradition, though we add an intermediate stage of (possible) imitation. We examine some of the questions that were the focus in the previous literature, namely the relation between market structure and innovation incentives; and the possibility of spillovers through imitation. The main difference in our approach is that we explicitly consider the level of firm dominance and the extent of imitation lags, in particular how these two measures interact in terms of welfare implications.

There is a recent related literature looking at R\&D incentives when a dominant firm owns an essential component. Farrell and Katz (1999) show that the dominant firm may have excessive incentives to invest in the complementary component and thus squeeze out the competition. Choi and Stefanadis (2001) argue that tying the essential and complementary components may create a barrier to entry: it requires a firm to be successful in both markets in order to successfully enter. Gilbert and Riordan (2006) show that tying leads to foreclosure and possibly an increase in social welfare. In these papers, the focus is on the interaction between tying decisions and the incentives to innovate. By contrast, we focus on the effects of increased firm dominance. We abstract from the source of the dominant firm's advantage (or rival firm's disadvantage), assuming instead that consumers are willing to pay more for the dominant firm's product. As in Farrell and Katz (1999), Choi and Stefanadis (2001), Gilbert and Riordan (2006), we consider a framework with $\mathrm{R} \& \mathrm{D}$ decisions followed by price competition. ${ }^{8}$

Also related to our paper is the literature on imitation and innovation incentives: Gallini (1992), Cadot and Lippman (1995), Bessen and Maskin (2000). These papers focus primarily on the effect of imitation lags on the incentives to innovate. For example, Cadot and Lippman show that innovation incentives may be non-monotonic on imitation lags. By contrast, our focus is on the effects of firm dominance on innovation incentives for a given innovation lag.

A recent, closely related paper, is Miller (2006). He considers a natural monopoly with uncertainty about demand and asymmetric potential entrants.

as a reduced form (Futia, 1980) or through the explicit modeling of a race in time (Loury, 1979; Dasgupta and Stiglitz, 1980a,b; Reinganum, 1981, 1982, 1983).

${ }^{7}$ See for example D'Aspremont and Jacquemin (1988).

${ }^{8}$ One difference is that we assume uncertain R\&D success and obtain a unique equilibrium. By contrast, Gilbert and Riordan (2006) consider a deterministic R\&D technology and obtain multiple equilibria, some in mixed strategies. 
Table 1: Timing of the model.

1. Firms simultaneously invest in R\&D.

- Firms observe R\&D outcome.

- Laggard imitates leader (if applicable).

2. Firm simultaneously set prices.

- Consumer chooses one of the firms and buys one unit.

In this situation, the disadvantaged potential entrant may have very low incentives to enter. In fact, if entry is successful, thus signalling that demand is favorable, then the advantaged entrant will follow suit. This may result in an equilibrium with too little entry. The structure of Miller's model is quite different from ours. However, the qualitative implications of the two models are similar.

\section{Model}

Suppose that two firms, 0 and 1 , simultaneously invest in R\&D. In order to achieve a probability of success $r_{i}$ a firm must pay a cost $\frac{1}{2} r_{i}^{2}$. If successful (probability $r_{i}$ ), firm $i$ gets a product of quality $q_{H}$. If unsuccessful (probability $1-r_{i}$ ) firm $i$ 's product is worth $q_{L}$. Let $g \equiv q_{H}-q_{L}$ be the gain from technical progress. The success probabilities of the two firms are independent.

Consumers are willing to pay $q_{1}$ for firm 1's product and $q_{0}+b$ for firm 0 's, where $q_{i}$ is firm $i$ 's quality level. That is, firm 0 has an advantage, perhaps because it controls a complementary product such as an operating system. After learning the value of $q_{i}$, each firm has the option of imitating its rival. By imitating firm $j$, firm $i$ 's quality becomes $q_{i}=q_{j}-l$. The value of $l$ measures imitation lags.

Once the values of $q_{i}$ have been determined (including, possibly, imitation), firms compete in prices. For simplicity, we assume there is one consumer buying one unit from one of the firms, whichever firm maximizes the difference between valuation and price. We normalize production costs to zero.

Throughout the paper, we make the following assumptions about the parameters $b, l$, and $g$.

Assumption $1 \quad b<l<1<g$. 
Table 2: Notation.
$q \quad$ Quality level
$g$ Innovation gain: $g \equiv q_{H}-q_{L}$
$l \quad$ Imitation lag
$b \quad$ Firm 0's extra value
$r_{i} \quad$ Firm $i$ 's level of R\&D, $i=0,1$
$V_{i} \quad$ Firm $i$ 's expected value, $i=0,1$
$C S$ Consumer surplus
$S S \quad$ Social surplus

The assumption that $l$ is lower than $g$ corresponds to imperfect protection of intellectual property. This implies that it is optimal for a firm with a lower interim quality $q$ to imitate its rival. We therefore simplify the second stage of the game by assuming that, in the case where only one firm is successful in $\mathrm{R} \& \mathrm{D}$, the unsuccessful firm imitates the successful one. If $b>l$, then firm 1 could never be the quality leader, even if firm 1's R\&D were successful and firm 0's failed. If this were the case, firm 1 would not invest in R\&D at all. ${ }^{9}$ The assumption that $l<1$ ensures that our equilibria are interior. ${ }^{10}$ Finally, the assumption $g>1$ reflects the idea that innovation is important.

The timing of the game is summarized in Table 1, whereas Table 2 lists the model's notation.

As usual, we solve the game backwards, beginning with the second-stage pricing game and then solving the $\mathrm{R} \& \mathrm{D}$ stage. There are four possible events: both firms' R\&D are successful, just firm 0 is successful, just firm 1 is successful, or neither is successful. For each such event, Table 3 summarizes its probability, the willingness of consumers to pay for each firm's product, the equilibrium price, each firm's profit (gross of R\&D costs), consumer surplus and social surplus (again gross of R\&D costs).

For example, the probability that Firm 0 is successful and Firm 1 is not (the event in the second column) is $r_{0}\left(1-r_{1}\right)$. Consumers' willingness to pay for firm 0's product in this event is $q_{H}+b=q_{L}+g+b$, and so on. More

\footnotetext{
${ }^{9}$ In this case, firm 0 would also underinvest in $R \& D$ from the point of view of social surplus maximization, but this would just be because intellectual property protection is imperfect $(l<1<g)$. There would not be any strategic effects.

${ }^{10}$ If $l>1$ then there is a corner solution in which $r_{0}=1$ and $r_{1}=0$. If $l-b>1 /(1-b)$ then there is a second corner solution in which $r_{1}=1$ and $r_{0}=b$.
} 
Table 3: Consumer surplus, social surplus and firm gross profit as a function of R\&D outcome.

\begin{tabular}{|l|l|l|l|l|}
\cline { 2 - 5 } \multicolumn{1}{c|}{} & \multicolumn{4}{c|}{ R\&D success event } \\
\cline { 2 - 5 } \multicolumn{1}{c|}{ Both } & Firm 0 only & \multicolumn{1}{c|}{ Firm 1 only } & \multicolumn{1}{c|}{ Neither } \\
\hline Probability & $r_{0} r_{1}$ & $r_{0}\left(1-r_{1}\right)$ & $\left(1-r_{0}\right) r_{1}$ & $\left(1-r_{0}\right)\left(1-r_{1}\right)$ \\
\hline Prob. notation & $P_{\text {both }}$ & $P_{\text {inc }}$ & $P_{\text {riv }}$ & $P_{\text {none }}$ \\
\hline Willingness to pay 0 & $q_{L}+g+b$ & $q_{L}+g+b$ & $q_{L}+g-l+b$ & $q_{L}+b$ \\
\hline Willingness to pay 1 & $q_{L}+g$ & $q_{L}+g-l$ & $q_{L}+g$ & $q_{L}$ \\
\hline Price & $b$ & $l+b$ & $l-b$ & $b$ \\
\hline Firm 0's gross profit & $b$ & $l+b$ & 0 & $b$ \\
\hline Firm 1's gross profit & 0 & 0 & $l-b$ & 0 \\
\hline Consumer Surplus & $q_{L}+g$ & $q_{L}+g-l$ & $q_{L}+g-l+b$ & $q_{L}$ \\
\hline Gross Social Surplus & $q_{L}+g+b$ & $q_{L}+g+b$ & $q_{L}+g$ & $q_{L}+b$ \\
\hline
\end{tabular}

generally, equilibrium prices are as follows: the firm with higher willingness to pay sets a price equal to the difference to the willingness to pay for the rival's product; the rival firm, in turn, sets price equal to zero. In equilibrium, consumers choose the firm charging a positive price (which we designate as equilibrium price). Consumer surplus is the difference between willingness to pay and price for the firm with higher willingness to pay; and gross social surplus is the willingness to pay for the firm with higher value of willingness to pay.

\section{$3 \quad$ Firm dominance and innovation}

We first solve for the equilibrium of the R\&D game. Suppose initially that the game is symmetric $(b=0)$. In this case, firm $i$ only makes any profits in the event that it is the only successful innovator. This event occurs with probability $r_{i}\left(1-r_{-i}\right)$ (where $r_{-i}$ is the rival's research effort); and the gross profit in this event is just equal to the innovation lag $l$. Therefore, in the symmetric case, the marginal benefit to firm $i$ of research effort is $\left(1-r_{-i}\right) l$. Given quadratic costs $\frac{1}{2} r_{i}^{2}$, the marginal cost to firm $i$ of increasing its research effort is equal to that effort level, $r_{i}$. Thus, each firm's reaction curve is linear 


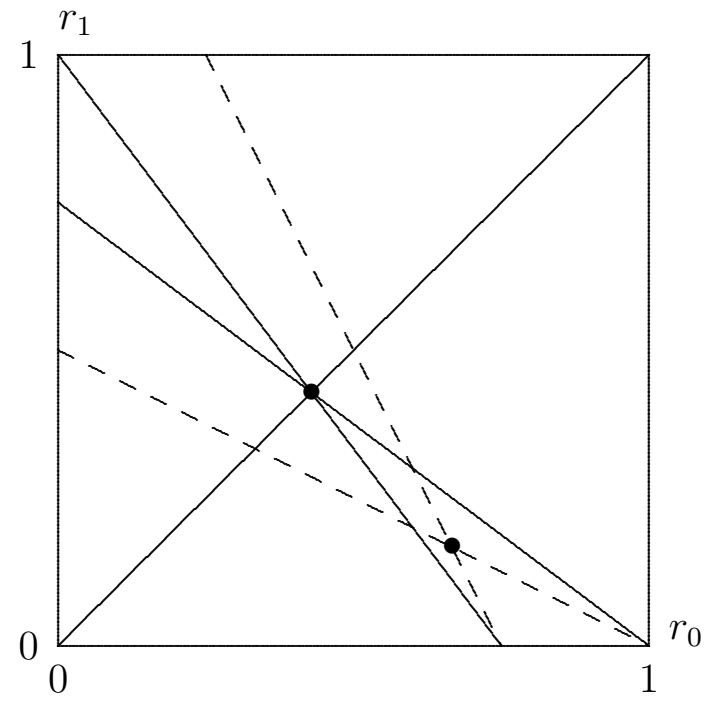

Figure 1: Reaction curves for $l=\frac{3}{4}$, and $b=0$ (solid lines), $b=\frac{1}{4}$ (dashed lines).

with intercepts at $r_{i}=l$ when $r_{-i}=0$ and $r_{i}=0$ when $r_{-i}=1$. This symmetric case is shown by the solid lines in Figure 1. The equilibrium is at $r_{i}^{e}=r_{-i}^{e}=\bar{r}=l /(1+l)$. As one would expect, as the innovation lag (or intellectual property protection) $l$ increases, each firm's equilibrium R\&D effort increases. Notice, however, that $\bar{r}<\frac{1}{2}$ for all $l<1$.

Now consider the case where the dominant firm has an advantage $b>0$. Not surprisingly, the dominant firm's expected profit is now larger and the rival's is smaller. For changes in incentives, however, the only event that matters is that in which the dominant firm's R\&D fails and the rival firm's R\&D succeeds (the event with probability $P_{r i v}:=r_{1}\left(1-r_{0}\right)$ ). This is the only event in which the dominant firm does not produce, and hence the only event in which it does not get an additional profit of $b$. It is also the only event in which the rival firm does produce, and hence the only event in which it suffers a reduction in profits of $b$. Thus, the dominant firm's marginal benefit of research effort is now increased to $\left(1-r_{1}\right) l+r_{1} b$. Its reaction curve rotates clockwise around its $r_{1}=0$ intercept inducing higher values of $r_{0}$. The rival firm's marginal benefit of research effort is reduced to $\left(1-r_{0}\right)(l-b)$. Its reaction curve rotates anti-clockwise around its $r_{1}=0$ intercept, inducing lower values of $r_{1}$. The new reaction curves are shown by the dotted lines in 


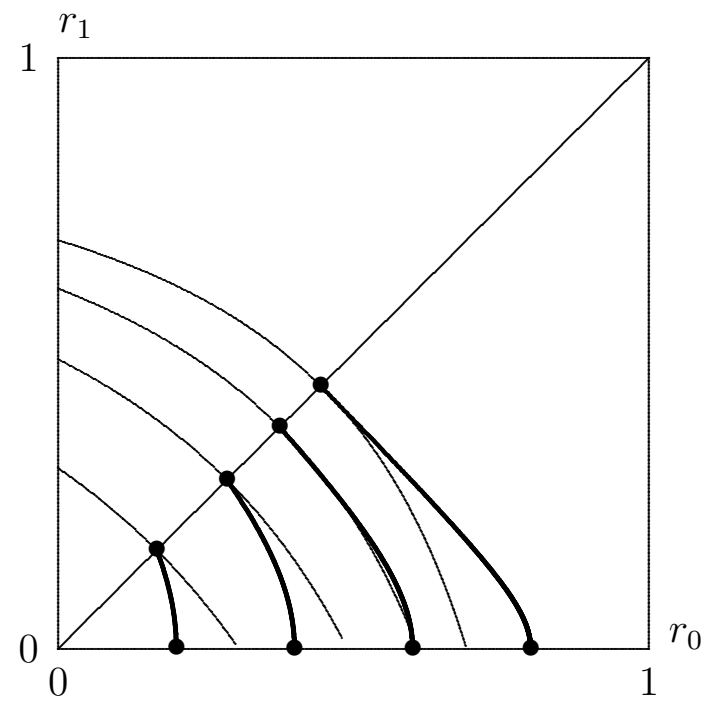

Figure 2: Effect of an increase in $b$ (from 0 to $l$ ) for four values of $l(0.2,0.4$, $0.6,0.8)$.

Figure 1. The equilibrium moves to the "south-east" and is given by

$$
r_{0}^{e}=\frac{l-(l-b)^{2}}{1-(l-b)^{2}} \quad \text { and } r_{1}^{e}=\frac{(1-l)(l-b)}{1-(l-b)^{2}} .
$$

It is easily checked that the sum of the two firms $\mathrm{R} \& \mathrm{D}$ efforts $r_{0}^{e}+r_{1}^{e}$ is increasing in the innovation lag $l$, but that this sum is still less than 1 for all $l<1$; that is, the equilibrium always lies below the second diagonal in Figure 1. The following proposition formalizes this discussion.

Proposition 1 An increase in $b$ implies an increase in firm 0 's equilibrium $R \mathscr{E} D$ effort, $r_{0}$, and a decrease in firm 1 's equilibrium RED effort, $r_{1}$.

This result describes a fundamental trade-off that permeates much of the analysis in the paper. In addition to the direct effect of firm dominance on consumer and social surplus, we must also consider the indirect effect in the firms' innovation incentives. The good news is that one of the firms, the dominant firm, has greater incentives; the bad news is that the other firm has lower incentives.

Which of these effects dominate? That is, what is the total effect of an increase in firm dominance, $b$, on the equilibrium overall probability of there being a successful innovation, $P_{\text {innov }}$ ? We can see from Figure 2 that the result depends on the size of innovation lags (or intellectual property protection) $l$. 
The dots on the $45^{\circ}$-line show equilibrium values for $\left(r_{0}, r_{1}\right)$ when $b=0$ at different levels of innovation lags $l$. Larger innovation lags induce more R\&D, so higher values of $l$ imply equilibria that are further out along the $45^{\circ}$-line. The thick lines show how these equilibria change as we increase $b$ holding $l$ fixed. Consistent with Proposition 2, increasing $b$ always moves the equilibria south-east reaching the $r_{1}=0$ axis when $b=l$. The thinner lines in the figure, concave to the origin, represent points at which the probability of a successful innovation is equal, that is, iso- $P_{\text {innov }}$ curves. We can see that increasing $b$ reduces the overall probability of innovation when innovation lags is small, but increasing $b$ increases the overall probability of innovation when innovation lags are large.

To understand this result, notice that even if both firms are undertaking $R \& D$, it only takes one $R \& D$ success to generate an innovation. We can write the overall probability of a success as the sum of the probabilities that each firm's R\&D is successful minus the probability that these successes duplicate:

$$
\begin{aligned}
P_{\text {innov }} & =1-\left(1-r_{0}^{e}\right)\left(1-r_{1}^{e}\right) \\
& =\left(r_{0}^{e}+r_{1}^{e}\right)-r_{0}^{e} r_{1}^{e} \\
& =R_{\text {tot }}-P_{\text {both }}
\end{aligned}
$$

where $R_{t o t}$ is the total research effort of the two firms and $P_{b o t h}$ is the probability of duplication. Thus, we can divide the impact of an increase in $b$ into two effects: a total effort effect $\Delta R_{t o t}$, and a duplication effect $\Delta P_{b o t h}$. The following lemmas describes these effects.

Lemma 1 Total research effort $R_{\text {tot }}$ is decreasing in b. The absolute size of this effect is decreasing in $l$ (with $\lim _{l \rightarrow 0} \frac{d R_{\text {tot }}}{d b}=-1$ and $\lim _{l \rightarrow 1} \frac{d R_{\text {tot }}}{d b}=0$ ).

Lemma 2 The probability of duplicate successes $P_{b o t h}$ is decreasing in $b$. The absolute size of this effect is small when $l$ is small (i.e., $\lim _{l \rightarrow 0} \frac{d P_{\text {both }}}{d b}=0$ ).

That is, the total research effort effect and the duplication effect work in opposite directions on the probability of innovation. Formal proofs are given in the appendix but an intuition is as follows. For total research effort, we already know from Proposition 1 that $r_{0}^{e}$ is increasing in $b$ and $r_{1}^{e}$ is decreasing in $b$. In both cases, the change in incentives depends on the same event, that in which only the rival firm's R\&D succeeds. Thus, the increase in the marginal benefit of research effort for the dominant firm as we increase $b$ is proportional to the rival firm's probability of success, $r_{1}$. The reduction in the marginal 
benefit of research effort for the rival firm as we increase $b$ is proportional to the dominant firm's probability of failure, $\left(1-r_{0}\right)$. At all equilibria, however, $r_{0}^{e}+r_{1}^{e}<1$; that is, the rival firm's probability of success $r_{1}^{e}$ is smaller than the dominant firm's probability of failure $\left(1-r_{0}^{e}\right)$. Thus, the increase in the marginal incentive for the dominant firm's research effort is smaller than the decrease in the corresponding marginal incentive for the rival firm. Hence $R_{t o t}$ is decreasing in $b$. As $l$ increases, however, the sum of research efforts $r_{0}^{e}+r_{1}^{e}$ increases toward one; that is, the rival firm's probability of success $r_{1}^{e}$ becomes close to the dominant firm's probability of failure $\left(1-r_{0}^{e}\right)$. This reduces the difference between the changes in the two firms' marginal incentives to $R \& D$ and hence reduces the total research effort effect.

For the duplication effect, given any fixed total research effort, if we reallocate that effort away from symmetry toward just one firm, then we reduce the probability of duplication (and hence increase the probability of innovation). We know from Proposition 2 that increasing $b$ shifts research effort from the rival firm to the dominant firm. The fact (Lemma 1) that it also reduces total effort only reduces further the probability of duplicate successes. Hence $P_{b o t h}$ is decreasing in $b$. When $l$ is small, however, the research efforts of both firms are small, and so the probability that both firms succeed is very small; that is, the duplication effect becomes of second order.

We are now ready to state formally the effect of changes in $b$ on the probability of innovation. Proposition 2 is concerned with small changes in the advantage of the dominant firm.

Proposition 2 Consider a small increase in firm dominance $b$. There exists a threshold $\bar{l}(b)$ such that the probability of innovation decreases as we raise $b$ if and only if the innovation lag $l$ is smaller than $\bar{l}(b)$, where $0<\bar{l}(b)<1$ if $b \in(0,1)$.

Figure 3 illustrates Proposition 2. The curved line represents points where $d P_{\text {innov }} / d b=0$. To the left of this line, $d P_{\text {innov }} / d b<0$, and to the right $d P_{\text {innov }} / d b>0$. A formal proof is in the appendix but the intuition follows directly from the lemmas above: when $l$ is small, duplication effects are small and the total effort effect dominates; when $l$ is large, total effort effects are small and the duplication effect dominates.

Figure 3 shows that the critical level of $l, \bar{l}(b)$, is equal to 1 for $b=0$ or $b=1$. When $b=0$, that is, around symmetry, small reallocations of effort (leaving total effort constant) have only a second-order effect on the probability of duplication (the iso- $P_{\text {innov }}$ curves all have slope -1 at the $45^{\circ}$-line). Hence 


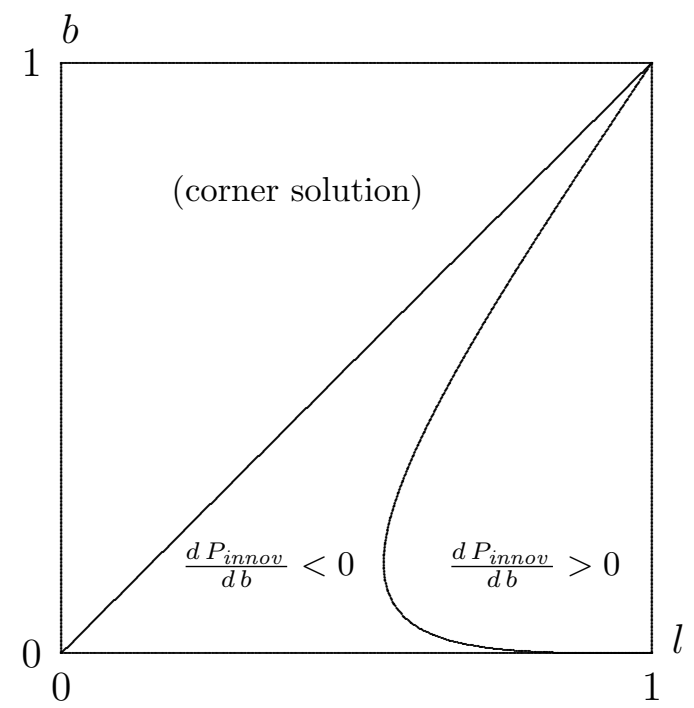

Figure 3: Illustration of Proposition 2. P denotes the probability of innovation.

the duplication effect is second order around $b=0$; the total effort effect dominates, and so $d P_{\text {innov }} / d b<0$. In terms of Proposition 3 , this means that $\bar{l}(0)=1$.

For $b=1$, notice that the rival firm's expected payoff is given by $(l-b)(1-$ $\left.r_{0}\right)$. At $l=b=1$, both terms in brackets are zero, and so a small decrease in $b$ has no effect on $r_{1}$. The dominant firm's expected payoff, in turn, is given by $\left(1-r_{1}\right) l+r_{1} b$. Since $r_{1}=0$ and $r_{1}$ does not change with $b$, it follows that $r_{0}$ does not change either. We conclude that $d P_{\text {innov }} / d b=0$ at $l=b=1$, as Figure 3 indicates.

In addition to this local result, we are interested in how the probability of innovation changes as we change from $b=0$ to $b=l$. At $b=0$, we are in a symmetric duopoly. At $b=l$, the advantage of the dominant firm is such that we are in an effective monopoly in which only the dominant firm undertakes R\&D.

Proposition 3 Consider an increase in b from 0 (symmetric duopoly) to $b=l$ (monopoly). The probability of innovation increases if and only if $l>\frac{\sqrt{5}-1}{2}$.

The exact cut-off value for $l$ stems from the details of the model, but the intuition is the same as before. When $l$ is small, the total effort effect dominates. When $l$ is large, the duplication effect dominates. For example, as $l$ approaches 1 , at monopoly $(b=l)$, only the dominant firm undertakes R\&D. 
Its efforts, and hence the probability of an innovation, approach 1 . At symmetry $(b=0)$, both firms are active and their R\&D efforts each approach $1 / 2$, so the total R\&D effort is the same. But now the probability of a successful innovation is only $3 / 4$. This is the effect of duplication.

\section{Consumer surplus}

What is the effect of an increase in firm dominance $b$ on consumer surplus? As before, it depends on the size of the innovation lag $l$, but now also on the social gains to innovations $g$. From Table 3 , we can write consumer surplus as

$$
\begin{aligned}
C S & =q_{L}+P_{\text {both }} g+P_{\text {inc }}(g-l)+P_{\text {riv }}(g-l+b) \\
& =q_{L}+P_{\text {innov }}(g-l)+P_{\text {both }} l+P_{\text {riv }} b
\end{aligned}
$$

The last term is a direct effect. Consumers gain directly from the quality improvement $b$ but only in the event in which only the rival firm's R\&D is successful. In that event, the advantage of the dominant firm limits the price that the rival firm can charge. In all other events, the dominant firm wins the sale and, though the good sold incorporates the quality improvement $b$, the price fully captures this increase in quality. Thus the size of the direct effect of an increase in $b$ on consumer surplus depends on $P_{\text {riv }}:=\left(1-r_{0}\right) r_{1}$. We already know from the previous section that this probability is small when $l$ is small and when $b$ is large. In both these cases, the rival firm has low incentive to undertake R\&D.

In addition, increasing $b$ has three indirect effects on consumer surplus. First: whenever there is a successful innovation, consumers gain (at least) the difference between the quality improvement and the innovation lag, $g-l$. An immediate implication is that, if the quality gain of innovation $g$ is large, then consumer surplus increases if and only if the probability of innovation increases. That is, If $g$ is large, the qualitative results of Propositions 2 and 3 apply to consumer surplus.

When $g$ is small or intermediate, other indirect effects can matter. Second: from Lemma 2, we already know that increasing $b$ decreases the probability of duplicate $R \& D$ successes, $P_{b o t h}$. In the last section, we were only concerned with increasing the probability of innovation, and duplicate $R \& D$ successes were no help. But consumers gain from duplicate successes since increased competition reduces prices. Thus, decreasing $P_{b o t h}$ is bad for consumers. Third: we also know from the previous section that increasing $b$ 
decreases $P_{\text {riv }}$, reducing consumer surplus. Since the second and third indirect effects are negative, the sum of the indirect effects are negative whenever $\Delta P_{\text {innov }}<0$, which again returns us to Propositions 2 and 3. For example, when $l$ is small $\Delta P_{\text {innov }}<0$. The indirect effects on consumer surplus, however, are also negative when $l$ is large relative to $g$. To see this, recall that $P_{\text {innov }}=R_{\text {tot }}-P_{\text {both }}$. Thus we can write consumer surplus as

$$
\begin{aligned}
C S & =R_{\text {tot }}(g-l)-P_{b o t h}(g-l)+P_{b o t h} l+P_{\text {riv }} b \\
& =R_{\text {tot }}(g-l)+P_{\text {both }}(2 l-g)+P_{\text {riv }} b .
\end{aligned}
$$

The probability of duplication appears twice. It hurts surplus (by an amount equal to $g-l$ ) by reducing the probability of innovation, but it helps consumers (by an amount equal to $l$ ) by increasing competition. Thus, when $l>2 g$ duplication is a net gain to consumers. By Lemmas 1 and 2 and Proposition 2 , we know that total effort, the probability of duplication and the probability that only the rival succeeds are all decreasing in $b$. Thus, if $2 l>g$, all indirect effects of changing $b$ on consumer surplus are negative.

The following proposition combines the effects from the above discussion for a small changes in the advantage of the dominant firm.

Proposition 4 Consider a small increase in firm dominance b. If the social gains to innovation $g$ are large, then consumer surplus moves in the same direction as the probability of innovation as we raise b (see Proposition 2). For lower values of $g$, consumer surplus may decrease even as the probability of innovation increases as we raise $b$ if both $b$ and $l$ are large.

As in the previous section, we are also interested in large changes in firm dominance from symmetry $(b=0)$ to effective monopoly $(b=l)$.

Proposition 5 Consider an increase in b from 0 (symmetric duopoly) to $b=l$ (monopoly). If the social gains to innovation $g<2$, then consumer surplus declines.

For an intuition, first notice that at both $b=0$ and $b=l$, the term $P_{\text {riv }} b$ is zero. That is, the direct effects are irrelevant to this comparison. Second, recall from Proposition 3 that, when $l$ is large, the large reduction in duplication as we move to effective monopoly leads to an increase in the probability of innovation. For consumer surplus, however, duplication has both positive and negative effects. As $l$ approaches and then exceeds $g / 2$, the net negative effect of duplication first becomes small and then reverses sign. Thus, once $l$ is large, the reduction in duplication as we move to effective monopoly has either a small effect and eventually a negative effect on consumer surplus. 


\section{Social surplus}

We now consider how changes in firm dominance affect social surplus. There are two important differences with respect to our discussion of consumer surplus. First, we now ignore how surplus is split between consumers and firms. Second, we must now take into account the costs of R\&D.

From Table 3, we can write social surplus as

$$
\begin{aligned}
S S & =q_{L}+P_{\text {both }}(g+b)+P_{\text {inc }}(g+b)+P_{\text {riv }}(g)+P_{\text {none }} b-c_{0}-c_{1} \\
& =q_{L}+P_{\text {innov }}(g)+\left(1-P_{\text {riv }}\right) b-c_{0}-c_{1}
\end{aligned}
$$

where $c_{i}$ is the cost of firm $i$ 's R\&D efforts. Notice the contrast between consumer and social surplus. From a social point of view, total benefit is the same when both firms innovate as when only the dominant firm innovates. The only difference is how that surplus is split between consumers and firms. For consumers, however, a second innovator increases competition and brings about an extra benefit of $l$, as we saw in the previous section.

The contrast between consumer and social surplus is particularly drastic with respect to the effects of $b$. As we saw in the previous section, consumers only benefit from $b$ when it is only the rival firm whose R\&D succeeds. In this case, a higher $b$ limits the extent of the rival firm's market power. From a social welfare point of view, however, the opposite is true: an increase in $b$ benefits society in all states except that in which only the rival firm's R\&D succeeds.

When we change $b$, as before, we get direct and indirect effects. The direct effect is $\left(1-P_{\text {riv }}\right)$ and it is always positive. As before, the indirect effects work through $r_{0}$ increasing and $r_{1}$ decreasing. Increasing firm 0's R\&D effort moves probability from the event that neither firm succeeds to the event that only firm 0 succeeds, and moves probability from the event that only firm 1 succeeds to the event that both succeed. It also increases costs. Thus, marginal net social benefit through changes in $r_{0}$ is given by

$$
\left(1-r_{1}\right) g+r_{1} b-c_{0}^{\prime}
$$

where $c_{0}^{\prime}$ represents marginal costs. (Table 3 may prove useful in understanding these values and the ones that follow.) Compare this with the marginal net private benefit of increasing $r_{0}$ to firm 0 (from section 3 ):

$$
\left(1-r_{1}\right) l+r_{1} b-c_{0}^{\prime}
$$


The difference between these terms is just $\left(1-r_{1}\right)(g-l)$ : the difference between the public and private gains when firm 0 is the only innovator. But in equilibrium, we know that this marginal net private benefit is zero (this is the envelope theorem). Thus, the net marginal social benefit is just $\left(1-r_{1}\right)(g-l)$.

Similarly, increasing firm 1's R\&D effort moves probability from the event that neither firm succeeds to the event that only firm 1 succeeds, and moves probability from the event that only firm 0 succeeds to the event that both succeed, and also affects costs. Thus, the marginal net social benefit through changes in $r_{1}$ is given by

$$
\left(1-r_{0}\right)(g-b)-c_{1}^{\prime}
$$

while the marginal net private benefit is given by

$$
\left(1-r_{0}\right)(l-b)-c_{1}^{\prime} \text {. }
$$

Again, the difference is just $\left(1-r_{0}\right)(g-l)$ : the difference between the public and private gains when firm 1 is the only innovator. And again, in equilibrium, we know that the marginal net private benefit is zero. Thus, the net marginal social benefit is just $\left(1-r_{0}\right)(g-l)$.

Putting this together, we find that the total indirect marginal effect of increasing $b$ on social surplus is given by

$$
(g-l)\left(\left(1-r_{1}\right) \frac{d r_{0}}{d b}+\left(1-r_{0}\right) \frac{d r_{0}}{d b}\right)=(g-l) \frac{d \text { Pinnov }}{d b}
$$

Recall that the direct effects are positive. Thus, for small increases in $b$, social surplus is increasing in $b$ whenever the probability of innovation is increasing in $b$; for example, when the innovation lag $l$ is large. As the innovation lag $l$ approaches zero, the weight $\left(1-P_{\text {riv }}\right)$ on the direct effect converges to one: it is almost never the case that the rival firm innovates. On the other hand, since $\frac{d P \text { innov }}{d b}=\frac{d R_{\text {tot }}}{d b}-\frac{d P b o t h}{d b}$, we know from our lemmas that the indirect effect converges to $-g$. Thus, when $l$ is mall (that is, for very small innovation lags), social surplus is decreasing in $b$ (like innovation and consumer surplus). To summarize,

Proposition 6 Consider a small increase in firm dominance b. If the social gains to innovation $g$ are large, then social surplus moves in the same direction as the probability of innovation as we raise $b$ (see Proposition 2). Even if $g$ is small, if the probability of innovation is increased as we raise $b$, then so is social surplus. 
Table 4: Summary of main results.

\begin{tabular}{|l|c|c|}
\hline \hline & $\begin{array}{c}\text { Small } \\
\text { change } \\
\text { in } b\end{array}$ & $\begin{array}{c}\text { Change } \\
\text { from } b=0 \\
\text { to } b=l\end{array}$ \\
\hline \hline \multirow{2}{*}{$\begin{array}{l}\text { Probability } \\
\text { of innovation }\end{array}$} & +ve iff $l>\bar{l}(b)$ & +ve iff $l>\frac{\sqrt{5}-1}{2}$ \\
\hline \hline \multirow{2}{*}{$\begin{array}{l}\text { Consumer } \\
\text { surplus }\end{array}$} & $\propto$ prob. innovation if $g$ large \\
\cline { 2 - 3 } & -ve if small $g$, large $b, l$ & - ve if $g<2$ \\
\hline \hline \multirow{2}{*}{$\begin{array}{l}\text { Social } \\
\text { surplus }\end{array}$} & $\propto$ prob. innovation if $g$ large \\
\cline { 2 - 3 } & \multicolumn{2}{|c|}{+ ve if $\Delta P_{\text {innov }}+$ ve } \\
\hline \hline
\end{tabular}

Note: + ve=positive - ve $=$ negative; $\propto=$ proportional to.

Once again, we are also interested in large changes in firm dominance from symmetry $(b=0)$ to effective monopoly $(b=l)$. For social surplus, these mirror the local results.

Proposition 7 Consider an increase in $b$ from 0 (symmetric duopoly) to $b=l$ (monopoly). If the probability of innovation is increased as we raise $b$, then so is social surplus.

\section{Summary and extensions}

Table 4 summarizes the main results in the paper. First, we have shown that an increase in firm dominance $b$ increases the probability of innovation if and only if imitation lags $l$ are large. Second, if the gains from innovation are sufficiently large, then the effects on consumer and social surplus have the same sign as the effects on the probability of innovation. Third, an increase in $b$ has a positive direct effect on social surplus, and so an increase in the probability of innovation is a sufficient condition for an increase in social surplus. Finally, an increase in $b$ may have a negative effect on consumer surplus through a decrease in the probability of duplication, which in turn may lead to a decrease in consumer surplus even when the probability of innovation increases.

One important extension of our model concerns the nature of firm dominance. While most agree that Microsoft has a competitive advantage over ri- 
Table 5: Consumer surplus, social surplus and firm gross profit as a function of R\&D outcome.

\begin{tabular}{|l|l|l|l|l|}
\cline { 2 - 5 } \multicolumn{1}{c|}{} & \multicolumn{4}{c|}{ R\&D success event } \\
\cline { 2 - 6 } \multicolumn{1}{c|}{ Both } & \multicolumn{1}{c|}{ Firm 0 only } & Firm 1 only & \multicolumn{1}{c|}{ Neither } \\
\hline Probability & $r_{0} r_{1}$ & $r_{0}\left(1-r_{1}\right)$ & $\left(1-r_{0}\right) r_{1}$ & $\left(1-r_{0}\right)\left(1-r_{1}\right)$ \\
\hline Willingness to pay 0 & $q_{L}+g$ & $q_{L}+g$ & $q_{L}+g-l$ & $q_{L}$ \\
\hline Willingness to pay 1 & $q_{L}+g-d$ & $q_{L}+g-l-d$ & $q_{L}+g-d$ & $q_{L}-d$ \\
\hline Price & $d$ & $l+d$ & $l-d$ & $d$ \\
\hline Firm 0's gross profit & $d$ & $l+d$ & 0 & $d$ \\
\hline Firm 1's gross profit & 0 & 0 & $l-d$ & 0 \\
\hline Consumer Surplus & $q_{L}+g-d$ & $q_{L}+g-l-d$ & $q_{L}+g-l$ & $q_{L}-d$ \\
\hline Gross Social Surplus & $q_{L}+g$ & $q_{L}+g$ & $q_{L}+g-d$ & $q_{L}$ \\
\hline
\end{tabular}

vals, there is wide disagreement as to what the source of such advantage is. In the previous sections, we have assumed that firm 0 , the dominant firm, is able to add value to its product. For example, in the Introduction we mentioned that, by controlling the operating system and other applications, Microsoft is better able to integrate each piece in the whole PC/Windows platform. But Microsoft may also prevent rival firms from integrating their software with the Windows operating system, thereby reducing the rival firm's value. ${ }^{11}$ In practice, it may be relatively easy to see that a firm is dominant but, in the absence of a smoking gun, it may be very hard to distinguish whether the dominant firm is adding value to its own product or reducing the value of its rival's product. It is therefore useful to know which of our results are robust to the nature of firm dominance.

To model the idea of reducing rival's value, we set $b=0$ and assume a negative premium $d$ on the rival's value. reducing the willingness to pay for the rival firm's product by $d$. Table 5 is then the analog of Table 3. An immediate observation is that each firm's profits (and hence its marginal incentive to

\footnotetext{
11 "Microsoft has ... engaged in practices which are often described as ... anticompetitive, such as the continual manipulation of the proprietary operating system to undermine rival's products, selective dissemination of information regarding the operating system's current and future functionality, ... pre-announcements of non-existent products to discourage consumer purchases of rival goods (sometimes referred to as "vaporware")" (Nader and Love, 1997).
} 
undertake R\&D) are the same as before except that $d$ has replaced $b$. In particular, this means that all our results from Section 3 about the probability of innovation still hold. For example, we learned in Section 3 that increasing firm dominance increases the probability of innovation if the innovation lag $l$ is large, and reduces the probability of innovation if the innovation lag is small. This result still applies.

Corollary 1 If the dominant firm advantage comes in the form of a reduction $-d$ in its rival's product value, then equilibrium RED effort levels of the two firms are exactly as if the advantage came in the form of an increase $b$ in the dominant firm's product value. Hence the comparative statics results of Propositions 2 and 3, and Lemmas 1 and 2 still apply $($ with $b=d)$.

Just as before, if the gains to innovation $g$ are large then the effect of increasing firm dominance on both consumer and social surplus follow the effect on the probability of innovation. Thus, for example, if $g$ is large, even when firm dominance is achieved by reducing a rival's value, such a reduction still increases social and consumer surplus when the innovation lag $l$ is large.

When $g$ is relatively small, however, we get different welfare effects of increasing dominance if dominance is in the form of reducing rival's value. Analogously to Section 4, we can write consumer surplus as

$$
C S=q_{L}+P_{\text {innov }}(g-l)+P_{\text {both }} l-\left(1-P_{\text {riv }}\right) d
$$

As before, the last term is a direct effect, but now it is negative. Moreover (using the fact that comparative statics are unchanged from Section 3 ) the term $-\left(1-P_{\text {riv }}\right) d$ is decreasing as we increase $d$. The probability of duplication, $P_{b o t h}$, is also decreasing in firm dominance. Thus, whenever increasing firm dominance $d$ reduces the probability of innovation, it also reduces consumer surplus. Also as before, we can also write consumer surplus as

$$
C S=q_{L}+R_{t o t}(g-l)+P_{b o t h}(2 l-g)-\left(1-P_{\text {riv }}\right) d
$$

Thus, if $g<2 l$, increasing firm dominance $d$ always reduces consumer surplus.

Moving to social surplus, analogously to before, we can write social surplus as

$$
S S=q_{L}+P_{\text {innov }} g-P_{\text {riv }} d-c_{0}-c_{1}
$$

Once again, we can divide the effect of increasing $d$ into direct and indirect effects. The direct effect, $-P_{\text {riv }}$, is negative. As in Section 5, we can reduce the indirect effects to

$$
(g-l) \frac{d P_{\text {innov }}}{d d}
$$


Thus, whenever innovation is decreased by raising $d$, social surplus is also. To summarize:

Corollary 2 If $g$ is large, then (as before) consumer and social surplus move in the same direction as the probability of innovation as we raise $d$. If $g$ is relatively small and the probability of innovation decreases as we raise $d$, then so do both consumer and social surplus. If $g<2 l$ then increasing $d$ always reduces consumer surplus.

It is not a surprise that reducing a rival value has worse welfare effects than increasing the dominant firm's value. What is perhaps more surprising is that the qualitative effects are so similar. In other words, our results are surprisingly robust with respect the nature of firm dominance.

Another robustness test is the nature of product market competition. We have assumed price competition with vertical differentiation only. While this implies profit functions that are not smooth (at the point where rivals have equal valuations), we believe our results are not knife-edged and would hold with some degree of horizontal product differentiation. The important feature is that the gap between dominant firm and rival firm in terms of marginal incentive for research effort increases as the value of $b$ increases.

Our assumption of a quadratic cost function is made for analytical convenience. It is clear from the proofs that our qualitative results do not depend on the exact functional form. Finally, we consider the case of one rival firm only. We believe the main results and intuitions would extend to the $n$ case as well. 


\section{Appendix: proofs}

Proof of Proposition 1: Solving for the Nash equilibrium, we get

$$
\begin{aligned}
& r_{0}^{e}=\frac{l-(l-b)^{2}}{1-(l-b)^{2}} \\
& r_{1}^{e}=\frac{(1-l)(l-b)}{1-(l-b)^{2}} .
\end{aligned}
$$

Straightforward differentiation implies that

$$
\begin{aligned}
\frac{d r_{0}^{e}}{d b} & =2 \frac{(1-l)(l-b)}{\left(1-(l-b)^{2}\right)^{2}} \\
\frac{d r_{1}^{e}}{d b} & =-\frac{(1-l)\left(1+(l-b)^{2}\right)}{\left(1-(l-b)^{2}\right)^{2}}
\end{aligned}
$$

The result then follows from Assumption 1.

Proof of Lemma 1: As seen before, the best-response functions are given by

$$
\begin{aligned}
r_{0}^{*} & =l-(l-b) r_{1} \\
r_{1}^{*} & =(l-b)\left(1-r_{0}\right) .
\end{aligned}
$$

Summing and differentiating (at the equilibrium values) yields

$$
\begin{aligned}
& \left(\frac{d r_{0}^{e}}{d b}+\frac{d r_{1}^{e}}{d b}\right)=-(l-b)\left(\frac{d r_{0}^{e}}{d b}+\frac{d r_{1}^{e}}{d b}\right)+r_{1}^{e}-\left(1-r_{0}^{e}\right) \\
& \left(\frac{d r_{0}^{e}}{d l}+\frac{d r_{1}^{e}}{d l}\right)=-(l-b)\left(\frac{d r_{0}^{e}}{d l}+\frac{d r_{1}^{e}}{d l}\right)+\left(1-r_{1}^{e}\right)+\left(1-r_{0}^{e}\right)
\end{aligned}
$$

Rearranging the top expression, we get

$$
(1+l-b)\left(\frac{d r_{0}^{e}}{d b}+\frac{d r_{1}^{e}}{d b}\right)=-\left(1-r_{0}^{e}-r_{1}^{e}\right)
$$

Since $r_{0}+r_{1}<1$, the right-hand side is negative, and the first part of the result follows: $\partial R_{\text {tot }} / \partial b<0$. Regarding the second part of the result, notice that $l=1$ and $b>0$ implies $r_{0}=1, r_{1}=0$, so the right-hand side of $(1)$ is zero. 
Rearranging the bottom expression yields

$$
\left(\frac{d r_{0}^{e}}{d l}+\frac{d r_{1}^{e}}{d l}\right)(1+l-b)=\left(1-r_{1}^{e}\right)+\left(1-r_{0}^{e}\right)
$$

Thus, total effort is increasing in $l$. Taking the cross derivative, we get

$$
\left(\frac{d^{2} r_{0}^{e}}{d b d l}+\frac{d^{2} r_{1}^{e}}{d b d l}\right)=-(l-b)\left(\frac{d^{2} r_{0}^{e}}{d b d l}+\frac{d^{2} r_{1}^{e}}{d b d l}\right)-\left(\frac{d r_{0}^{e}}{d b}+\frac{d r_{1}^{e}}{d b}\right)+\left(\frac{d r_{0}^{e}}{d l}+\frac{d r_{1}^{e}}{d l}\right)
$$

or

$$
\left(\frac{d^{2} r_{0}^{e}}{d b d l}+\frac{d^{2} r_{1}^{e}}{d b d l}\right)(1+l-b)=\frac{d R_{t o t}}{d l}-\frac{d R_{t o t}}{d b}>0
$$

For the limits, as $l \rightarrow 1$, if $b=0, r_{0}^{e}=r_{1}^{e} \rightarrow \frac{1}{2}$. If $0<b<l$, then $r_{0}^{e} \rightarrow 1$ and $r_{1}^{e} \rightarrow 0$. In either case, $\left(r_{1}^{e}+r_{0}^{e}\right) \rightarrow 1$ and hence $\frac{d R_{t o t}}{d b} \rightarrow 0$. As $l \rightarrow 0$ (with $b<l),\left(r_{1}^{e}+r_{0}^{e}\right) \rightarrow 0$ and hence $\frac{d R_{t o t}}{d b} \rightarrow-1$.

Proof of Lemma 2: Differentiating $P_{b o t h}$ we get

$$
\begin{aligned}
\frac{d\left(r_{0}^{e} \cdot r_{1}^{e}\right)}{d b} & =r_{1}^{e} \frac{d r_{0}^{e}}{d b}+r_{0}^{e} \frac{d r_{1}^{e}}{d b} \\
& =r_{1}^{e}\left(\frac{d r_{0}^{e}}{d b}+\frac{d r_{1}^{e}}{d b}\right)+\left(r_{0}^{e}-r_{1}^{e}\right)\left(\frac{d r_{1}^{e}}{d b}\right)
\end{aligned}
$$

The first term is negative since total effort is decreasing (Lemma 1). The second term is non-positive since $r_{1}^{e}$ is decreasing and $r_{0}^{e} \geq r_{1}^{e}$ (Proposition 1). For the limit, as $l \rightarrow 0$, both $r_{1}^{e} \rightarrow 0$ and $r_{0}^{e} \rightarrow 0$, so it is enough to show that neither of the derivatives $\frac{d r_{0}^{e}}{d b}$ or $\frac{d r_{1}^{e}}{d b}$ explode as $l \rightarrow 0$. This is easily checked by inspection of the equilibrium expressions.

Proof of Proposition 2: Computation establishes that

$$
\begin{aligned}
& \left.\frac{d P_{\text {innov }}}{d b}\right|_{b=0}=-\frac{1-l}{(1+l)^{3}}<0 \\
& \left.\frac{d P_{\text {innov }}}{d b}\right|_{b=l}=-(1-l)^{2}<0 .
\end{aligned}
$$

Moreover, solving $\frac{d P_{\text {innov }}}{d b}=0$ with respect to $l$ yields only two real roots: $l=1$ and

$$
l=\bar{l}(b)=1-\sqrt[3]{b(2-b)^{2}}+\sqrt[3]{b^{2}(2-b)}
$$


Notice that $\bar{l}(0)=\bar{l}(1)=1$ and $\bar{l}(b)<1$ for $b \in(0,1)$. By Lemmas 1 and 2 we know that $\frac{d P_{\text {innov }}}{d b}<0$ when $l$ is close to zero. Since $\frac{d P_{\text {innov }}}{d b}$ is continuous in $l, b$, we conclude that $\frac{d P_{\text {innov }}}{d b}<0$ if and only if $l<\bar{l}(b)$.

Proof of Proposition 3: At $b=0$, the equilibrium is symmetric with $r_{0}^{e}=r_{1}^{e}=r=l /(1+l)$. Thus, $\left.P_{\text {innov }}\right|_{b=0}=1-(1-r)^{2}=1-1 /(1+l)^{2}$. At $b=l$, only the dominant firm is active and $r_{0}=l$. Thus, $\left.P_{\text {innov }}\right|_{b=l}=l$. The result follows by direct calculation.

Proof of Proposition 4: Consumer surplus may be written as

$$
\begin{aligned}
C S & =q_{L}+P_{\text {both }} g+P_{\text {inc }}(g-l)+P_{\text {riv }}(g-l+b) \\
& =q_{L}+P_{\text {innov }}(g-l)+P_{\text {both }} l+P_{\text {riv }} b
\end{aligned}
$$

If $g$ is large enough, then $d C S^{e} / d b>0$ if and only if $d P_{\text {innov }} / d b>0$. This proves the first part of the proposition.

Computing the derivative of $C S^{e}$ with respect to $b$ and equating $b$ to zero we get

$$
\left.\frac{d C S^{e}}{d b}\right|_{b=0}=\frac{2 l-l^{2}(1-l)-g(1-l)}{(1+l)^{3}} .
$$

Immediate inspection reveals that the derivative ranges from $-g<0$ for $l=0$ to $2>0$ for $l=1$. Moreover, the derivative of the numerator with respect to $l$ is given by $3 l^{2}+2(1-l)+g$, which is positive under Assumption 1. It follows that, for small values of $b$, there exists an $\bar{l}(b)$ such that consumer surplus is decreasing in $b$ if and only if $l<\bar{l}(b)$.

Consider now the case when $b=l$. Computation establishes that

$$
\left.\frac{d C S^{e}}{d b}\right|_{b=l}=-(1-l)\left(g(1-l)+l^{2}\right)<0 .
$$

Together with the previous result, this implies that for high values of $l$, consumer surplus is maximal for an intermediate value of $b$.

Proof of Proposition 5: Straightforward computation yields

$$
\begin{aligned}
\left.C S\right|_{b=l} & =q_{L}+(g-l) l \\
\left.C S\right|_{b=0} & =\frac{l(g l+2(g-l))}{(1+l)^{2}}
\end{aligned}
$$


We now show that, given $l<g<2$, we have $\left.C S\right|_{b=0}>\left.C S\right|_{b=l}$. If fact, if $l^{2}+l-1>0$ then

$$
\begin{aligned}
\left.C S\right|_{b=0}-\left.C S\right|_{b=l} & =\frac{l\left(l\left(l^{2}+2 l-1\right)-g\left(l^{2}+l-1\right)\right)}{(1+l)^{2}} \\
& >\frac{l\left(l\left(l^{2}+2 l-1\right)-2\left(l^{2}+l-1\right)\right)}{(1+l)^{2}} \\
& =\frac{l(1-l)^{2}(2+l)}{(1+l)^{2}} \\
& >0 .
\end{aligned}
$$

On the other hand, if $l^{2}+l-1<0$ then

$$
\begin{aligned}
\left.C S\right|_{b=0}-\left.C S\right|_{b=l} & =\frac{l\left(l\left(l^{2}+2 l-1\right)-g\left(l^{2}+l-1\right)\right)}{(1+l)^{2}} \\
& >\frac{l\left(l\left(l^{2}+2 l-1\right)-l\left(l^{2}+l-1\right)\right)}{(1+l)^{2}} \\
& =\frac{l^{3}}{(1+l)^{2}} \\
& >0 .
\end{aligned}
$$

which concludes the proof.

Proof of Proposition 6: In text.

Proof of Proposition 7: Recall that social surplus is given by $S S=q_{L}+$ $P_{\text {innov }}(g)+\left(1-P_{\text {riv }}\right) b-c_{0}-c_{1}$. At $b=0$, this reduces to

$$
\left.S S\right|_{b=0}=q_{L}+\left.P_{\text {innov }}\right|_{b=0}(g)-\bar{r}^{2}
$$

where $\bar{r}$ is the symmetric equilibrium R\&D effort level $l /(1+l)$. At $b=l$, social surplus reduces to

$$
\begin{aligned}
\left.S S\right|_{b=l} & =q_{L}+\left.P_{\text {innov }}\right|_{b=l}(g)+b-\frac{1}{2} l^{2} \\
& =q_{L}+\left.P_{\text {innov }}\right|_{b=l}(g)+l-\frac{l^{2}}{2}
\end{aligned}
$$

Thus, $\left.S S\right|_{b=l}-S S_{b=0}>\left.P_{\text {innov }}\right|_{b=l}-\left.P_{\text {innov }}\right|_{b=0}$. 
For small $l,\left.S S\right|_{b=l}>S S_{b=0}$ if and only if $d S S / d b>0$. The second part of the proposition thus follows from Proposition 6 . 


\section{References}

Bessen, Jim, AND ERIC Maskin (2000), "Sequential Innovation, Patents, and Imitation," MIT Working Paper 00-01 (revised 2002).

Cadot, Olivier, and Steven A. Lippman (1995), "Barriers to Imitation and the Incentive to Innovate," UCLA.

Choi, Jay Pil, and Christodoulis Stefanadis (2001), "Tying, Investment, and the Dynamic Leverage Theory," Rand Journal of Economics $32,52-74$.

Cohen, Wesley M, and Richard C Levin (1989), "Empirical Studies of Innovation and Market Structure," in Schmalensee and Willing (Eds), Handbook of Industrial Organization, North-Holland.

Dasgupta, Partha, and Joseph Stiglitz (1980a), "Uncertainty, Industrial Structure, and the Speed of R\&D," Bell Journal of Economics 11, $1-28$.

Dasgupta, Partha, And Joseph Stiglitz (1980b), "Industrial Structure and the Nature of Innovative Activity," Economic Journal 90, 266-293.

D’Aspremont, Claude and Alexis Jacquemin (1988), "Cooperative and Noncooperative R\&D in Duopoly With Spillovers," American Economic Review 78, 1133-1137.

Farrell, Joseph, And Michael Katz (2000), "Innovation, Rent Extraction, and Integration in Systems Markets," Journal of Industrial Economics 48, 413-432.

Futia, C A (1980), "Schumpeterian Competition," Quarterly Journal of Economics 93, 675-695.

Gallini, Nancy T. (1992), "Patent Policy and Costly Imitation," Rand Journal of Economics 23, 52-63.

Gilbert, Richard J., And Michael H. Riordan (2006), "Product Improvement and Technological Tying in a Winner-Take-All Market," forthcoming, Journal of Industrial Economics. 
Loury, Glenn (1979), "Market Structure and Innovation," Quarterly Journal of Economics 93, 395-410.

Miller, David A (2006), "Invention Under Uncertainty and the Threat of Ex Post Entry," USCD.

Reinganum, Jennifer (1981), "Dynamic Games of Innovation," Journal of Economic Theory 25, 21-41.

Reinganum, Jennifer (1982), "A Dynamic Game of R\&D: Patent Protection and Competitive Behavior," Econometrica 50, 671-688.

Reinganum, Jennifer (1983), "Uncertain Innovation and the Persistence of Monopoly," American Economic Review 74, 61-66.

Schumpter, Joseph A (1942), Capitalism, Socialism, and Democracy, New York: Harper. 